\title{
Arbitraje en disputas ambientales: Análisis comparado
}

\author{
Daniel Robalino Orellana ${ }^{1}$ \\ Leyre Suárez Dávalos ${ }^{2}$
}

\begin{abstract}
Sumario
1. Introducción. 2. El arbitraje en disputas ambientales. $2.1 \mathrm{El}$ arbitraje ambiental en la esfera del derecho local. 2.2 El arbitraje ambiental en la esfera del derecho internacional. 2.3 Arbitraje Ambiental en materia de inversiones. 3. Consideraciones finales.
\end{abstract}

\section{INTRODUCCIÓN}

En los últimos años, el resguardo al medio ambiente se ha convertido en un tema de alto interés para los estados. Existe una tendencia de protección en respuesta a la exigencia de un mayor control y regulación de actividades que causan impacto ambiental. Esto, a decir de JUNCEDA MORENO, se ha traducido en una constitucionalización de los principios ambientales. ${ }^{3}$

El Ecuador no ha sido ajeno a este fenómeno. Ahora existe mayor control por parte del Estado y los ciudadanos han adquirido conciencia ambiental, siendo así que ahora no es inusual la existencia de controversias ambientales, o de procesos de control

1. Abogado Asociado en el despacho Paz Horowitz Robalino Garcés, titulado por Colegio de Jurispnradencia de la Universidad San Francisco de Quito.

2. Abogada, Colegio de Jurisprudencia de la Universidad San Francisco de Quilo. Asociado en el despacho Paz Horowitz, Robalino Garcés.

3. JUNCEDA MORENO, Javier. "Arbitraje, Actividades Extractivas y Normativa Internacional Ambiental: el Caso del Amazonas". Universidad Intemacional de Cataluña, p. 2. 
de la actividad privada por parte de las autoridades ambientales, sean municipales o estatales.

En Ecuador, el arbitraje se ha convertido en una alternativa viable para la solución de controversias, sin embargo, la legislación ecuatoriana no prevé, expresamente, la posibilidad de someter disputas ambientales a arbitraje. Por este hecho, en Ecuador no existen centros de arbitraje especializados en solución de disputas ambientales.

Contrario sensu, en países como Perú, España y Estados Unidos se ha implementado, a través de legislación específica, arbitraje en disputas ambientales, generando métodos alternativos para solución de tales controversias de manera célere y altamente especializada.

Por lo expuesto, a continuación realizaremos un análisis en el cual se expone brevemente: (i) el arbitraje ambiental en el derecho comparado, distinguiendo arbitraje por disputas de carácter patrimonial derivadas de daño ambiental -contractual o extracontractual-de las disputas netamente ambientales; $y$, (ii) el arbitraje ambiental en la esfera internacional del derecho, con enfoque en el arbitraje comercial derivado de incumplimiento de obligaciones ambientales contractuales, así como en disputas de inversión al amparo de tratados y convenios entre Estados.

\section{El arbitraje en disputas ambientales}

El arbitraje ha sido definido como un método alternativo de solución de conflictos, en esencia contractual, en el cual las partes acuerdan someter la disputa a la decisión de un tercero ${ }^{4}$. En este

4. Binghan Lisa B. y David CAmeron Prel... "Arbitration on Environmental Disputes that cross National Boundaries". En: Encyclopedia of Life Support Systems. Oxford: EOLSSS, 2002, p. 3.

E) arbitraje es un método consensual, cuasi-judicial de resolver un conflicto. Es una forma alternativa de solución de controversias, usualmente utilizada cuando las negociaciones voluntarias y la mediación han fallado. En el arbitraje las partes acuerdan sobre un juez o jueces privados, a quienes facultan para resolver los asuntes legales, de hecho o ambos. 
sentido GIL ECHEVERRI señala que el arbitraje es un "procedimiento jurisdiccional sui generis mediante el cual (...) se defiere la solución de conflictos privados transigibles, a un cuerpo igualmente colegiado integrado por árbitros, los que transitoriamente quedan investidos de jurisdicción" ${ }^{\prime \prime}$. A su vez, Trelles Castillo ha definido al arbitraje en los siguientes términos:

"Por el arbitraje el Estado otorga a los particulares la potestad de resolver controversias respecto a materias de libre disposición, siendo ejecutable la decisión final siempre que dentro del proceso se observen los principios de igualdad, audiencia y contradicción o, en términos del derecho procesal constitucional, salvnguardando el debido proceso" $^{\prime \prime}$.

Con los antecedentes expuestos, es necesario centrarse en el arbitraje ambiental. Este nace por la necesidad de un medio de solución de conflictos más rápido, eficiente y especializado para tratar las disputas ambientales, que por su naturaleza son sensibles, tanto para el afectado como para el infractor. En este sentido MCCUTCHEON ha sostenido que el arbitraje, para disputas ambientales, se ha convertido en el método preferido, ya que provee soluciones rápidas, eficientes y apropiadas a disputas complicadas dentro de un tiempo razonable ${ }^{7}$.

En disputas referentes a contaminación o perturbaciones ambientales, la parte afectada se enfrenta a un sistema de justicia copado de casos y a jueces que no tienen ninguna experticia en materia ambiental; lo cual desincentiva las denuncias y acciones ambientales. El profesor JUNCEDA MORENO explica ilustrativamente este problema:

"Arbitration is a consensual, quasi-judicial means of resolving conflict. It is a form of alternative dispute resolution (or ADR) often used after voluntary negotiation and mediation have failed to resolve the conflict. In arbitration the parties to a conflict mutually agree upon a private judge or judges whom they empower to decide disputed issues of law, fact, or both".

5. Salcedo Verduga, Emesio Citando a Jorge Hemán Gil. Echieverri, El arhitraje: la justicia aliernativa. Guayaquil: Distrilib, Segunda edición, 2007, p. 29.

6. Trelles Castillo, José Antonio. "Arbitraje y Medio Ambiente: Una Relación que Contamina". En: http://blog.pucp.edu pe, 2009.

7. McCutcieon, David. "Arbitration of Environmental Disputes". FMC Law, 2012, p. 1. 
"El uso de las herramientas legales disponibles por quienes denuncian la lesión ambiental por éstn o aquella actividad industrial en cualquier Estado, suele arrojar un saldo que no cuesta calificar como decepcionante. Salvo notables excepciones, quienes animosamente se aproximan a los mecanismos jurisdiccionales ordinarios en aras de la defensa ambiental, bien pronto descubren el desencanto enmascarado en la pétrea resistencia de la actuación administrativa, origen habitual del problema" 8

Estas trabas impuestas por la justicia ordinaria han generado un creciente apoyo en jurisdicciones, tanto nacionales como internacionales, al arbitraje ambiental. MCCUTCHEON en su artículo "Arbitration of Environmental Disputes" desarrolla las diferentes ventajas del arbitraje ambiental frente a las cortes, iniciando por la especialización.

Es así que al contar con un árbitro o tribunal con conocimiento en derecho ambiental ayuda en primer lugar, a una evaluación correcta de la evidencia presentada por las partes, ya que en su mayoría se trata de informes técnicos complejos; en segundo lugar, contribuye a una cuantificación correcta de los daños y la correspondiente indemnización. Finalmente, un árbitro o tribunal con experticia en estos temas, puede evaluar fácilmente los estándares aplicables en reclamos ambientales. ${ }^{9}$

Otra ventaja expuesta por el antes mencionado autor, es la confidencialidad del arbitraje. Esta confidencialidad, como explica MCCUTCHEON, no afecta el derecho a la defensa de las partes, ya que éstas siguen obligadas a observar los principios procesales como lealtad procesal, transparencia e inmediación. Sin embargo, esta confidencialidad beneficia a las partes, sobre todo en casos de alto perfil, para evitar el escrutinio público y la interferencia de factores externos. Además, se evita el descrédito de las partes involucradas en el proceso y de sus expertos o asesores. ${ }^{10}$

8. JUNCEDA MORENO, Javier. "Arbitraje, Actividades Extractivas y Normativa Intemacionał Ambiental: el Caso del Amazonas". Universidad Internacional de Cataluña, p. 2.

9. MCCUTCHEON, David. "Arbitration of Environmental Disputes". FMC Law, 2012, p. 1.

10. MCCutcheon, David. "Arbitration of Environmental Disputes". FMC Law, 2012, pp. 1 y 2 
A pesar de las ventajas expuestas por el antes mencionado autor, él al igual que otros autores reconocen que la mayoría de jurisdicciones han preferido someter las disputas ambientales a las cortes locales, particularmente cuando se requiere la adopción de medidas cautelares que impliquen el cese inmediato de los actos nocivos para el ambiente.

"Sin embargo, existen instancias en las cuales son preferibles los procedimientos ante cortes locales, como en el caso donde una orden judicial es necesaria para detener un derrame contaminante, o en los casos en que las partes desean establecer un precedente legal vinculantes en el futuro"11.

En síntesis la doctrina ha establecido al arbitraje ambiental como un método efectivo para resolver disputas en esta materia en los siguientes términos:

"El arbitraje ambiental debería tener como finalidad resolver las controversias, respecto a la protección del derecho de la propiedad privada de eventuales daños causados por contaminación o perturbaciones ambientales provocados por terceros, es justo en este último donde eventualmente el procedimiento arbitral tendria posibilidades de desarrollarse, agregamos que podrín tener un mayor desarrollo si el arbitraje se aplica en conflictos sobre recursos naturales y como forma de terminar un conflicto ambiental". ${ }^{12}$

Como se desprende de esta definición, la mayoría de la doctrina y la legislación comparada han limitado la arbitrabilidad de disputas ambientales a aquellas que afectan los derechos patrimoniales, dejando afuera del scope de tales procesos los daños ambientales que afectan derechos difusos al medio ambiente, más no al patrimonio de un particular. Este punto será tratado con mayor profundidad en las siguientes secciones.

11. McCutcheon, David. "Arbitration of Environmental Disputes". FMC Law, 2012, p. 2: "There are still instances however where a court proceeding may be preferable, such as cases where an immediate injunction is required to stop a spill of contamination, or where the parties wish to establish a legal precedent that would be binding in the event of future simitar factual situations"

12. Vidal Ramos, Roger. "Arbitraje Ambiental en Perú". Lima: Ratio Juris, p. 3. 


\subsection{El arbitraje ambiental en la esfera del Derecho local}

Existen diferentes legislaciones que han regulado el arbitraje ambiental en la esfera local. Entre estas podemos citar como ejemplos a la legislación peruana y estadounidense. Sin embargo, la mayoría de ellas han previsto arbitraje ambiental para daños patrimoniales causados por contaminación. Esta limitación ha producido ciertas críticas, ya que existe una distinción entre daños ambientales y daños patrimoniales. Esta distinción ha sido reconocida a nivel mundial por la doctrina más autorizada en derecho ambiental e incluso por las cortes locales de Ecuador ${ }^{13}$.

Esta crítica ha llevado a inferir que las legislaciones antes detalladas, que limitan el arbitraje ambiental a disputas sobre daños patrimoniales, no están regulando el daño ambiental per se, ya que este tipo de daños de cualquier manera sería arbitrables por tratarse de daño civil extracontractual; por lo tanto, no existe una innovación en estas legislaciones frente a otras, como la ecuatoriana, que no han regulado el arbitraje ambiental.

En este sentido el autor peruano TRELLES expresa su parecer respecto a la insuficiencia en la legislación peruana sobre el arbitraje ambiental en los siguientes términos:

"Pensamos que en realidad no existe arbitralidad en materias relativas al medio ambiente, asi como tampoco relativas a delitos ofaltas, sino respecto al resarcimiento por responsabilidad civil (extracontractual) derivado de los daños o perjuicios ocasionados a una persona o grupo de personas determinado y, que escapan del ámbito ambiental o penal y se incorporan al civil, patrimonial y disponible. Por tanto, dichas controversias pueden resolverse mediante Arbitraje, no por su inclusión en la Ley General del Ambiente, ni por su precisión en la Ley General de Arbitraje, sino en virtud de su naturaleza patrimonial y de libre disposición." ${ }^{14}$

13. Véase el fallo de la Corte Superior de Nueva Loja, Julio 29 de 2009, en el caso presentado en contra de OCP por daños en las propiedades de los scñores Josć Maria Amaguay, Wilson Moreta Armijo y Ángel Ordóñez, por la construcción del olcoducto. En este fallo la Corte hizo una clara distinción entre cl daño ambiental como la afectación de un derecho difuso y el daño civil a la propicdad.

14. Trelles Castillo, José Antonio. "Arbitraje y Medio Ambiente: Una Relación que Contamina". En: http//blog.pucp.edu.pe/, 2009. 
Esta breve descripción es el principal problema que han enfrentado las legislaciones para reglamentar el arbitraje ambiental y requiere un análisis mayor sobre como ha sido concebido este tema en las diferentes legislaciones y como se ha regulado en nuestro país.

Como se ha expuesto en el presente artículo, las legislaciones de otros países han establecido normas específicas y han reglamentado el arbitraje ambiental, si bien como señala TRELLES CASTILLO, no siempre esta normativización ha sido apropiada; se debe reconocer el esfuerzo y el adelanto que significa la preocupación de estos países por someter disputas ambientales a arbitraje. A continuación analizaremos el arbitraje ambiental en la legislación peruana, estadounidense, española y ecuatoriana.

\subsubsection{El arbitraje ambiental en Perí}

El desarrollo del arbitraje ambiental en Perú se explica por el crecimiento en las disputas ambientales sobre todo en actividades extractivas como le explica VIDAL RAMOS:

"Ante el notable auge del arbitraje en el Perí, es fundamental resaltar la posibilidad de acudir a un arbitraje en materia ambiental, la Ley General del Ambiente (en adelante LGA) incorpora al arbitraje como mecanismos de solución de controversias, qué duda cabe que ante el boom de las inversiones y explotación en recursos naturales de diversas Actividades Extractivas (Minería, Hidrocarburos y Forestal), la institución del Arbitraje Ambiental deberia de tomar mayor importancia en la solución de conflictos ambientales". ${ }^{15}$

La actual Ley General de Arbitraje del Perú (Ley No. 026572), establece la posibilidad de someter las disputas ambientales a arbitraje, esta norma prescribe:

Articulo 1o.- Disposición general.- Pueden someterse a arbitraje las controversias determinadas o determinables sobre las cuales las par-

15. Vibal Ramos, Roger. “Arbitraje Ambiental en Perú". Lima: Ratio Juris, p. 3. 
tes tienen facultad de libre disposición, asi como aquellas relations a materia ambiental pudiendo extinguirse respecto de ellas el proceso judicial existente o evitando el que podrí promoverse; excepto:

1. Las que versan sobre el estado o la capacidad civil de las personas, ni las relations a bienes o derechos de incapaces sin la previa autorización judicial.

2. Aquellas sobre las que ha recaído resolución judicial firme, salvo la consecuencias patrimoniales que surjan de su ejecución, en cuanto conciernan exclusivamente a las partes del proceso.

3. Las que interesan al orden público o que versan sobre delitos ofaltas. Sin embargo, si podrá arbitrarse sobre la cuantía de la responsabilidad civil, en cuanto ella no hubiera sido fijada por resolución judicial firme.

4. Las directamente concernientes a las atribuciones ofunciones de imperio del Estado, o de personas o entidades de derecho público ${ }^{16}$.

Incluso, la Ley de Arbitraje faculta al Estado peruano y a sus dependencias someter a arbitraje las disputas con compañías locales $\mathrm{e}$ internacionales domiciliadas en territorio peruano:

"Artículo 20.- Arbitraje del Estado.- Pueden ser sometidas a arbitraje nacional, sin necesidad de autorización previa, las controversias derivadas de los contratos que el Estado Peruano y las personas de derecho público celebren con nacionales o extranjeros domiciliados, asi como las que se refieren a sus bienes. Para los efectos de este Artículo, el Estado comprende el Gobieno Central, los Gobiernos Regionales y Locales y sus respectivas dependencias. Las empresas estatnles de derecho privado o de economía mixta pueden acordar libremente y sin requisito de previa autorización que las controversias derivadas de los contratos que celebren con nacionales o extranjeros domiciliados o que se refieran a sus bienes, sean sometidos a arbitraje nncional."17

A diferencia de los establecido en la legislación ecuatoriana, en el sistema peruano no se requiere una autorización previa, ni existe un límite para someter las disputas a arbitrajes internacionales ${ }^{18}$.

16. El subrayado no es parte del texto original.

17. Ley General de Arbitraje Peruana.

18. Ver: Ley de Arbitraje y Mediación Ecuador, Articula 4. 


\subsubsection{El arbitraje ambiental en España}

Otro país que ha incorporado en su legislación arbitraje ambiental es España. El autor VIDAL RAMOS explica que en este país se ha venido utilizando el arbitraje ambiental administrativo para solucionar controversias y culminar procedimientos administrativos $^{19}$. Sin embargo, los autores critican a la legislación española por establecer muchos límites al arbitraje ambiental, por ejemplo la limitación de la actuación de los ciudadanos:

"[...] dichas soluciones queden habitualmente a disposición de las propias administraciones y no dejen tampoco en manos de los ciudadanos el derecho subjetivo a impetrar dicho desenlace arbitral" ${ }^{20}$.

Si bien en España se prevé el arbitraje ambiental administrativo, que es un paso importante en la solución de conflictos entre privados y estado, la limitación a la actuación de los ciudadanos no es la única barrera que enfrenta este sistema. Como expone JUNCEDA MORENO, el sistema español carece de un desarrollo normativo y jurisprudencial suficiente para permitir la aplicación del arbitraje ambiental administrativo:

"En algunos otros ordenamientos internos, en cambio, la cuestión que aqui abordamos precisa aún del necesario desarrollo, tanto normativo como jurisprudencial y dogmático. Sin perjuicio de las alusiones genéricas a ln actividad arbitral de las Administraciones en la legislación general y sectorial, en la particular cuestión del arbitraje ambiental apenas se cuenta con instrumentos normativos (en España, tan sólo con una Ley regional, la de Protección general del Medio Ambiente del País Vasco 3/1998, de 27 de febrero, en cuyo articulado dispone que los procedimientos derivados de su aplicación podrán concluir mediante acuerdo entre el solicitante y la Administración competente y terceros afectados)"21.

Este autor resume la normativa española, aplicable al arbitraje ambiental, como limitada y particular, lo cual genera un

19. Vidal Ranos, Roger. "Arbitraje Ambiental en Perú". Lima: Ratio Juris, p. 2.

20. Vidal Ramos, Roger. “Arbitraje Ambiental en Perú". Lima: Ratio Juris, p. 2.

21. JunCen MORENo, Javier. "Arbitraje, Actividades Extractivas y Normativa Internacional Ambiental: el Caso del Amazonas". Universidad Internacional de Cataluña, p. 3. 
cierto relego del arbitraje frente a los procedimientos administrativos de impugnación.

“En el sistema juridico español, la vigente Ley de Régimen Juridico de las Administraciones Públicas y del Procedimiento Administrativo Comuin, permite el sometimiento a arbitraje de los sujetos públicos territoriales en términos tan sui generis como limitados: cuando una Ley especifica y sectorial así lo justifique, y siempre que dicho eventual arbitraje se sustancie "ante órganos colegiados o comisiones específicas no sometidas a instrucciones jerárquicas", y en cualquier caso, con respeto a los principios, garantías y plazos que esta Ley de procedimiento general reconoce a los ciudadanos y a los interesados en todo expediente administrativo. En su consecuencia, el marco del arbitraje de derecho píblico quedará limitado a su función sustitutiva de los métodos de impugnación conocidos, de los rectursos administrativos, y a poco más, siempre que, eso si, una Ley así lo prevea." 22 (las negrillas me corresponden).

En conclusión, la doctrina ha visto al sistema español como insuficiente para solucionar disputas ambientales y se ha evidenciado la necesidad de un mayor desarrollo normativo y jurisprudencial, para que sea un verdadero método eficiente de resolución de controversias y de garantía del respeto del derecho ambiental.

\subsubsection{El arbitraje ambiental en Estados Unidos}

Estados Unidos ha sido considerado como un ejemplo de desarrollo normativo y jurisprudencial en el desarrollo del arbitraje ambiental administrativo. Desde el año 1996 con la promul-

gación del Administrative Dispute Resolution Act, se implementó un sistema para solución de controversias verdaderamente ambientales, como contaminación, conservación de recursos y protección atmosférica; el cual se maneja a través de la suscripción de un convenio arbitral entre las partes afectadas con el patrocinio de una agencia estatal.

22. JunCeda Moreno, Javier. "Arbitrajc, Actividades Extractivas y Normativa Intemacional Ambiental: el Caso del Amazonas". Universidad Internacional de Cataluña, pp. 3 y 4. 
"En derecho comparado, Estados Unidos cuenta desde hace años con un imaginativo sistema de resolución alternativa de conflictos, en sede administrativa ambiental -Administrative Dispute Resolution Act (ADR) en su versión de 1996-, técnica que prevé expresamente medidas alternativas a las jurisdiccionales para la resolución de conflictos, entre ellas, el arbitraje administrativo ambiental, usualmente utilizado por su agencia de protección ambiental en materia de conservación y recuperación de recursos, de protección atmosférica, o de contaminación de aguas, operando a partir de la suscripción por las partes afectadas (grupos o colectivos ambientales y operadores económicos), de un contrato de compromiso con sometimiento expreso a la fórmula arbitral ${ }^{\prime 23}$.

El desarrollo normativo y jurisprudencial, en materia de arbitraje ambiental, que tiene la jurisdicción norteamericana ha permitido soluciones oportunas a problemas de carácter técnico.

"Así pues, ejemplos como el norteamericano bien podrín extenderse a los demás Estados, posibilitando respuestas tempranas a asuntos cada vez más presentes en nuestras sociedades. No pueden nuestras gentes ni muestras Administraciones seguir confiando en exceso en las instituciones jurisdiccionales actuales, y máxime en graves dilemas como los socio ambientales, tan necesitados de soluciones técnicas precisas aunque consensuadas" 24 .

\subsubsection{El arbitraje ambiental en Ecuador}

Respecto de la protección del medio ambiente, la Constitución Política de la República de Ecuador del año 1998 consagró el derecho de todos los ciudadanos a vivir en un medio ambiente sano y declaró de interés público a la preservación del medio ambiente, la prevención de la contaminación, la recuperación de los espacios naturales degradados y el desarrollo sustentable ${ }^{25}$.

23. JUNCEDA MORENO, Javier. “Arbitraje, Actividades Extractivas y Normativa Internacional Ambiental: el Caso del Amazonas". Universidad Intemacional de Cataluña, p. 3.

24. JunCEDA MORENO, Javier. "Arbitraje, Actividades Extractivas y Normativa Intemacional Ambiental: el Caso del Amazonas". Universidad Internacional de Cataluña, p. 3.

25. Constitución Politica 1998:

Art, 86.- El Estado protegerá el derecho de la población a vivir en un medio ambiente sano y ecológicamente equilibrado, que garantice un desarrollo sustentable. Velará para que este derecho no sea afectado y garantizara la preservación de la naturaleza. 
Posteriormente, la Ley de Gestión Ambiental introdujo varios cambios importantes en la legislación ambiental ecuatoriana. Uno de los más importantes fue conceder acción pública para denunciar violaciones de normas medio ambientales; otorgando legitimación pasiva a cualquier persona natural o jurídica para iniciar una acción en materia ambiental ${ }^{26}$. Adicionalmente, se fijó competencia en el Presidente de la entonces Corte Superior ${ }^{27}$, ahora Corte Provincial, para conocer las disputas ambientales.

En esta misma línea, la Constitución 2008, en vigencia, amplía aún más la protección al medio ambiente, invirtiendo la carga de la prueba en disputas sobre daños ambientales al demandado, haciendo imprescriptibles las acciones para perseguir el daño ambiental; y positivizando los principios de prevención y precaución. El artículo pertinente prescribe:

"Art. 396.- El Estado adoptará las políticas y medidas oportunas que eviten los impactos ambientales negativos, cuando exista certidumbre de daño. En caso de duda sobre el impacto ambiental de alguna acción u omisión, aunque no exista evidencia científica del daño, el Estado adoptará medidas protectoras eficaces y oportunas. La responsabilidad por daños ambientales es objetiva. Todo daño al ambiente, ademós de las sanciones correspondientes, implicará tam-

Se declaran de interés pủblico y se regularán conforme a la ley:

1. La preservación del medio ambiente, la conservación de los ecosistemas, la biodiversidad y la integridad del patrimonio genético del pais.

2. La prevención de la contaminación ambiental, la recuperación de los espacios naturales degradados, el manejo sustentable de los recursos naturales y los requisitos que para estos fines deberan cumplir las actividades públicas y privadas.

3. El establecimiento de un sistema nacional de áreas naturales protegidas, que garantice la conservación de la biodiversidad y el mantenimiento de los servicios ecológicos, de conformidad con los convenios y tratados internacionales.

26. Ley de Gestion Ambiental:

Art. 41.- Con e! fin ưe proteger los derechos ambientales individuales a colectivos, concédese acción pública a las personas naturales, juridicas o grupo humano para denunciar la violación de las normas de medio ambiente, sin perjuicio de la acción de amparo constitucional previsto en la Constitución Politica de la Repüblica.

27. Art. 42.- Toda persona natural, jurídica o grup̧o humano podrá ser oida en los procesos perales, civiles o administrativos, que se inicien por infracciones de caricter ambiental, aunque no hayan sido vulnerados sus propios derechos,

El Presidente de la Corte Superior del lugar en que se produzea la afectación ambiental, será el competente para conocer las acciones que se propongan a consecuencia de la misma. Si la afectación comprende varias jurisdicciones, la competencia correspondera a cualquicra de los presidentes de las cortes superiores de esas jurisdicciones. 
biên la obligación de restaurar integralmente los ecosistemas e indemnizar a las personas y comunidades afectadas.

Cada uno de los actores de los procesos de producción, distribución, comercialización y uso de bienes o servicios asumirá la responsabilidad directa de prevenir cualquier impacto ambiental, de mitigar y reparar los daños que ha causado, y de mantener un sistema de control ambiental permanente.

Las acciones legales para perseguir y sancionar por daños ambientales serán imprescriptibles".

Por otro lado, la Constitución 2008 reconoce, de manera expresa, a la institución arbitral como uno de los métodos alternativos de solución de controversias. En este sentido, el artículo 190 de la Constitución señala:

"Art. 190.- Se reconoce el arbitraje, la medinción y otros procedimientos alternativos para la solución de conflictos. Estos procedimientos se aplicarán con sujeción a la ley, en materias en las que por su naturaleza se pueda transigir.

En la contratación pública procederá el arbitraje en derecho, previo pronunciamiento favorable de la Procuraduria General del Estado, conforme a las condiciones establecidas en la ley". 28

A pesar del reconocimiento del arbitraje, la nueva Constitución ha limitado el sometimiento a arbitraje ante tribunales internacionales, el artículo 422 establece:

"Art. 422.- No se podrá celebrar tratados o instrumentos internacionales en los que el Estado ecuatoriano ceda jurisdicción soberana a instancias de arbitraje internacional, en controversins contractuales o de indole comercial, entre el Estado y personas naturales o jurídicas privadas.

Se exceptían los tratados e instrumentos internacionales que establezcan la solución de controversins entre Estados y ciudadanos en Latinoamérica por instancias arbitrales regionales o por órganos jurisdiccionales de designación de los países signatarios. No podrán

28. Vale mencionar que el pronunciamiento favorable del Procurador General del Estado, en materia de contratación pública, es ahora un requisito previo. La Constitución anterior (1998) y la Ley de Arbitraje y Mediación (1997) disponian que el dictamen del procurador debía pedirse "Si la cláusula arbitral se celebrara una vez surgida la controversia". 
intervenir jueces de los Estados que como tales o sus nacionales sean parte de la controversia.

En el caso de controversias relacionadas con la deuda externa, el Estado ecuntoriano promoverá soluciones arbitrales en función del origen de la deuda y con sujeción a los principios de transparencin, equidad y justicia internacional".

Sin perjuicio de lo anterior, la Ley de Arbitraje y Mediación (en adelante LAM) en su primer artículo define al sistema arbitral como "un mecanismo alternativo de solución de conflictos al cual las partes pueden someter de mutuo acuerdo, las controversias susceptibles de transacción, existentes ofuturas para que sean resueltas por los tribunales de arbitraje administrado o por árbitros independientes que se conformaren para conocer dichas controversias."

Adicionalmente, establece la capacidad para someterse a arbitraje en los siguientes términos y con los respectivos requisitos:

Art. 4.- Podrán someterse al arbitraje regulado en esta Ley las personas naturales o juridicas que tengan capacidad para transigir, cumpliendo con los requisitos que establece la misma.

Para que las diferentes entidades que conforman el sector puiblico puedan someterse al arbitraje, además de cumplir con los requisitos que establece esta Ley, tendrán que cumplir los siguientes requisitos adicionales:

a) Pactar un convenio arbitral, con anterioridad al surgimiento de la controversia; en caso de que se quisiera firmar el convenio una vez surgida la controversia, deberá consultarse al Procurador General del Estado, dictamen que será de obligatorio cumplimiento;

b) La relación jurídica a la cual se refiere el convenio deberá ser de carńcter contractual;

c) En el convenio arbitral deberá incluirse la forma de selección de los árbitros; $y$,

d) El convenio arbitral, por medio del cual la institución del sector público renuncia a la jurisdicción ordinaria, deberí ser firmado por la persona autorizada para contratar a nombre de dicha institución.

El incumplimiento de los requisitos señalados acarreará la nulidad del convenio arbitral. 
De las normas citadas se puede inferir que las disputas arbitrables son aquellas de carácter "transigible" ${ }^{\prime 29}$. En este sentido, el Código Civil establece:

"Art. 2354.- No vale la transacción sobre derechos ajenos o sobre derechos que no existen".

Siguiendo con está línea vale citar a Trelles CAstillo, quien al referirse a la arbitrabilidad del daño ambiental dice:

"Ella ha sido definida en la doctrina y en el derecho comparado como vinculada a la disponibilidad de las partes y a su derecho a transigir, ya sean éstas particulares o, el propio Estado a través de sus distintas entidades e instituciones. Tal disponibilidad se relaciona con los intereses esencialmente patrimoniales vinculados procesalmente a la materia sub litis, excluyente de efecto o alcance hacia los terceros desvinculados de la relación juridica-procesal y en si de la materia controvertida"30.31

Entonces, el problema radica en que los conflictos propiamente ambientales el sujeto pasivo afectado no es determinado, se trata de un derecho difuso. El autor VIDAL Ramos explica este punto con mayor detalle:

"El origen de este percance se debe a que en materin ambiental no existe un colectivo determinado e incluso determinable que posibilite su válida actuación como parte en un proceso arbitral, pues la legitimación procesal involucra el carícter positivo de participación y negativo de exclusión de los terceros ajenos a la controversia y cuyos derechos supuestamente se encuentran desvinculados". ${ }^{32}$

29. LAM: Art. 1.- El sistema arbitral es un mecanismo alternativo de solución de conflictos al cual las partes pueden someter de mutuo acuerdo, las controversias susceptibles de transacción, existentes o futuras para que sean resucltas por los tribunales de arbitraje administrado $\circ$ por árbitros independientes que se conformaren para conocer dichas controversias.

30. Trelles Castit.lo, José Antonio. "Arbitraje y Medio Ambiente: Una Relación que Contamira". En: http://blog.pucp.edu.pe/, 2009.

31. En Colombia la Ley 23 de 1991 (artículo 85) en concordancia con los articulo 65 de la Ley 446 de 1998 y 19 de la Ley 640 de $200 \mathrm{~L}$, disponen en términos generales que son asuntos conciliables todos aque!los susceptibles de transacción, desistimiento y aquellos qque expresamente determine la Ley. Por su parte, la Ley Marco Ambiental, Ley 99 de 1993, cstablece en su articulo 107, párrafo 2, que "Las normas ambientales son de orden público y no podrán ser objeto de transacción o de renuncia a su aplicación por tas autoridades o por los particulares".

32. Vidal. Ramos, Roger. “Arbitraje Ambiental en Perü". Lima: Ratio Juris, p. 5. 
Entonces, si bien existe un consenso en referencia a la posibilidad de someter disputas ambientales patrimoniales y contractuales a arbitraje, se requiere de un desarrollo normativo o jurisprudencial sobre la legitimación pasiva para someter disputas ambientales al conocimiento de tribunales arbitrales.

Lo anterior se vincula con las disputas ambientales contractuales. Si bien es conocido que el daño ambiental tiene naturaleza extracontractual, es usual incluir cláusulas relativas a responsabilidad ambiental en contratos para la ejecución de ciertas actividades extractivas o industriales de riesgo. Dichas cláusulas suelen incluir la obligación de observar la normativa ambiental ecuatoriana, realizar auditorías ambientales, entre otras.

Tales contratos, a su vez, contienen cláusulas arbitrales para la solución de controversias derivadas de su ejecución o incumplimiento, sometidas al conocimiento de tribunales arbitrales internacionales o locales. Sobre esto, El autor VIDAL RAMOS citando a BLANCO URIBE dice:

"[... ] al tratar el tema de la responsabilidad civil contractual en materia ambiental, que sería la proveniente del incumplimiento de un contrato, en el cual, de tener pactada la clausula de arbitramiento, el conflicto estaría siendo resuelto por el tribunal que se designe para estos efectos". 33

El arbitraje en tema de responsabilidad civil contractual en materia ambiental es más común en el ámbito internacional y será revisado en la siguiente sección.

\subsection{El arbitraje ambiental en el Derecho Internacional}

La protección al medio ambiente, en el derecho internacional, se encuentra disperso en distintas normas, incluyendo jurisprudencia y doctrina que constituye soft law. Existen varios instrumentos internacionales importantes en materia de protección 33. Vidal, Ramos, Roger. "Arbitraje Ambiental en Perü". Lima: Ratio Juris, p. 8. 
ambiental, los cuales han servidos, sobre todo para inspirar a las legislaciones locales a adoptar sus principios. Entre ellos podemos nombrar a convenciones no vinculantes como la Convención de Estocolmo de 1972, la Convención de Río de Janeiro de 1992.

Por otro lado hay otras como el Protocolo de Montreal sobre la capa de ozono y el de Kioto sobre el cambio climático. Finalmente, hay un grupo específico de normas sobre resolución de conflictos con tintes ambientales como el Protocolo para Resolución de Controversias sobre la Convención de Viena sobre Responsabilidad por Daños Nucleares.

Sin perjuicio de lo anterior, han existido importantes esfuerzos para la creación de un centro internacional de arbitraje, especializado en disputas ambientales. De manera particular, la creación de la Corte Internacional de Arbitraje y Conciliación Ambiental, en México en Noviembre de 1994. Esta corte fue creada específicamente para tratar temas ambientales, como su nombre lo indica, por 28 juristas de 22 países $^{34}$. Sin embargo, esta Corte no cuenta con un sistema efectivo de ejecución de laudos por lo que ha quedado relegada a la emisión de opiniones consultivas.

Otras cortes han tratado disputas ambientales en la esfera internacional. Por ejemplo, la Corte Internacional de Justicia (CIJ), en 1974, resolvió el caso Australia-Nueva Zelanda v. Francia por pruebas nucleares. Así mismo, la CIJ resolvió en 1997 el llamado caso Gabcikovo-Nagymaros, entre Hungría y Eslovaquia, por la construcción de esclusas en el Río Danubio; y en 2006 resolvió el caso "Papeleras" entre Argentina y Uruguay por contaminación en el río Uruguay.

Vale decir que existen otros casos ambientales resueltos por cortes internacionales, tales como el propuesto por Ecuador ante la Corte Interamericana de Derechos Humanos en razón de la fumigación de cultivos de coca en la frontera colombo-ecuatoriana ${ }^{35}$.

34. Eceizabarrena, Javier. "Corte Internacional de Arbitraje y Conciliación Ambiental". Eusko Ikaskuntza.

Revista Ecuatoriana de Arbitraje 255 
Sin perjuicio de lo anterior, es relevante señalar que en la Corte Permanente de Arbitraje (PCA) tiene, desde el año 2001 la denominadas "Reglas Medioambientales Opcionales"36. Las referidas reglas fueron redactadas por un comité de expertos en derecho ambiental y arbitraje, tomando como base las normas UNCITRAL para arbitraje comercial, siendo aplicables a controversias que involucren Estados. Estas reglas, como su nombre lo indica, son opcionales y para ser aplicables, es decir, para entrar dentro de la jurisdicción de la PCA deben ser aceptadas expresamente por las partes involucradas en el conflicto, sin embargo, una vez aceptadas, constituyen un waiver a la jurisdicción soberana de los Estados ${ }^{37}$.

\subsection{Arbitraje Ambiental en Materia de Inversiones}

En la actualidad existen aproximadamente 2700 tratados bilaterales de inversión (TBIs) alrededor del mundo ${ }^{38}$, además de algunos tratados multilaterales. Unos 140 países forman parte por lo menos de uno de estos tratados. La gran mayoría de TBIs fueron negociados y firmados en la década de $1990 .{ }^{39}$ Los TBIs establecen varios estándares de protección de la inversión como son: el trato justo y equitativo, la no expropiación sin compensación, el trato nacional, la no discriminación entre otros ${ }^{40}$.

35. ABED, Sheila "Cortes intemacionales para el medio ambiente" Programa Regional de Capacitacion en Derecho y Politicas Ambientales, pp. 144, 145 y 146.

36. Ver: Optional Rules for Arbitration of Disputes Relating to the Environment and/or Natural Resources, disponibles en www.pca-cpa.org

37. Ver Artículo 2 de las Reglas Medioambientales Opcionales. El texto original en inglés reza:

2. Agrecment by a party to arbitration under these Rules constitutes a waiver of any right of sovereign immunity from jurisdiction, in respect of the dispute in question, to which such party might otherwise be entilled. A waiver of immunity relating to the execution of an arbitral award must be explicitly expressed.

38. SUAREZ, lgnacio. "Particularidades del Acceso al Arbitraje Internacional en los Tratados Bilaterales de Inversión suscritos por la República del Ecuador". Revista Ecuatoriana de Arbitraje. Quito: Cevallos Editora Juridica, 2010, p. 63.

39. BOLetin Nümero 49 de la Red Oilwatch. Septiembre 2004

40. SCIREUER, Christoph. "Fair and Equitable Treatment (FET): Interaction with other Standards". Transnational Dispute Management. Vol. 4 Núm 5, septiembre 2007, pp, i y 2. 
Lo interesante de los TBIs es que establecen cláusulas de solución de controversias bajo el tratado y por ende bajo el derecho internacional. Estos estándares y cláusulas de solución de disputas protegen a la inversión ${ }^{41}$. El término inversión ha sido discutido largamente por lo tribunales y se ha basado en el lenguaje de cada tratado, pero la casuística y la doctrina han llegado al consenso de que los contratos son un tipo de inversión. Como ejemplo podemos citar la definición del Acuerdo para la Promoción y Protección Recíproca de Inversión entre la República de Ecuador y El Reino de España que dice:

"Art. 1.- Definiciones.- A los efectos del presente Acuerdo:

2.- Por "inversiones" se desigua todo tipo de haberes, tales como bienes y derechos de toda naturaleza, adquiridos de acuerdo con la legislación del país receptor de la inversión y en particular, aunque no exclusivamente, los siguientes:

- Derechos para realizar actividades económicas y comercinles otorgados por la Ley o en virtud de un contrato, en particular los relacionados con la prospección, cultivo, extracción o explotación de recursos naturales".

En este mismo sentido el Convenio entre el Gobierno de la República de Ecuador y el Gobierno de la República de Italia, sobre Promoción y Protección de Inversiones también incluye los derechos contractuales dentro de la definición de inversión:

Art. 1.- Definiciones: Para los fines del presente convenio:

1. El término "inversión" será interpretado en el sentido de cualquier tipo de bien invertido, antes o después de la entrada en vigor de este convenio, por una persona natural o jurídica de una de las Partes Contratantes en el territorio de la otra Parte Contratante, de conformidad con las leyes y reglamentos de dicha Parte, independientemente de la forma legal escogida o del marco legal respectivo.

41. Bisiof, Doak, James Crawford y Michael Reisman. Foreign Imvestment Disputes. La Haya: Kluwer Law, 2005. p. 9: An investment generally has certain distinguishing characteristics. First, it has a certain temporal duration. It does not involve a single sale. Second, the commitment by the investor (usually monetary) is substantial. Third, there is an expectation of profit. Forth, there is an undertaking of risk by the investor, and sometimes by the host government as well. Another frequent characteristic is the contribution of the investment to the development of the state, by building or enhancing its infrastructure or its cconomy. 
Sin limitar la generalidad de lo anterior, el término "inversión" incluye en particular, pero no exclusivamente:

e) Cualquier derecho económico al que tenga derecho por ley o bajo contrato y cualquier licencia y franquicia acordada de conformidad con las disposiciones vigentes sobre actividades económicas, incluyendo el derecho de exploración, extracciön y explotación de recursos naturales; $y$

Partiendo de que los derechos contractuales son una inversión, estos están protegidos por todos los estándares de trato del TBI. De tal forma que, una violación contractual puede ascender a, dependiendo de las circunstancias, violaciones de trato justo y equitativo, expropiación, discriminación, protección plena y seguridad. Entonces, el tribunal internacional será el llamado a determinar si la violación del contrato importó una violación de algunos de los estándares de trato.

Es bajo esta esfera de protección del TBI que pueden surgir disputas ambientales en materia de inversión. Como habíamos mencionado, muchos contratos contienen obligaciones ambientales y por ende la violación de dichas obligaciones pueden conllevar a la violación del contrato.

Sin embargo, los TBIs son instrumentos internacionales suscritos por Estados que benefician a los inversionistas, por lo tanto el Estado no puede acudir a dichos tribunales como demandante ya que en el tratado, en sí, no existe consentimiento por parte del inversionista. Entonces, en este caso, la jurisdicción del tribunal dependerá de la cláusula de solución de controversias pactada en el contrato administrativo. Sin embargo, existe la posibilidad de que el estado presente reclamos ambientales contractuales, en contra del inversionista, como contrademanda en un proceso iniciado por dicho inversionista en un reclamo de inversión.

La posibilidad o no de una disputa de naturaleza ambiental en las esferas del derecho internacional de las inversiones dependerá del lenguaje del tratado y de las esferas de protección del mismo. Este límite impuesto por el lenguaje se ha manifestado en 
un sinnúmero de ocasiones y en referencia a diferentes estándares y cláusulas de los tratados. ${ }^{42}$

En conclusión, el arbitraje en derecho internacional del las inversiones es una posibilidad para someter disputas ambientales al conocimiento de tribunales arbitrales, cuyos laudos podrán ayudar a dilucidar cuestionamientos en la materia que han surgido en el derecho local, a modo de soft law.

\section{ConSIDERACIONES FINALES}

Coincidimos con VIDAL RAMOs en que el arbitraje constituye una posibilidad respecto de la solución de disputas ambientales.

Los sistemas jurídicos estudiados ya reconocen y permiten el arbitraje de disputas ambientales de carácter patrimonial (por ser transigibles). Sin embargo, debemos reconocer que no son pocos los factores relativos al arbitraje ambiental que se resisten a admitir más de una conciliación de posturas, particularmente cuando concurran cuestiones de orden público.

Para que el arbitraje ambiental constituya un sistema claro, con menos zonas grises, será necesario que las normas $-o$ la jurisprudencia- resuelvan las interrogantes que existen entorno a las disputas ambientales que no tienen un legitimario pasivo determinado, es decir, cuando se deban tutelar derechos difusos.

Los sistemas arbitrales deberán evolucionar para permitir, como en el caso norteamericano, arbitraje ambiental administrativo, con normas procesales claras en donde el Tribunal Arbitral es un órgano altamente especializado y en donde las legitimación activa recae sobre un ente de gobierno determinado, logrando que el laudo sea exigible y oponible a terceros, lo que genera se-

42. Cremades, Bemardo. "Disputes Arising Out of Foreign Direct Investment in Latin America: A New Look at the Calyo Doctrine and Other Jurisdictional Issues". Disputc Resolution Journal. Vol. 59 Num. 2, Mayo 2004, uhttp://vlex.com/vid/disputes-arising-calvo-jurisdictional-61758215/ixzz/81QsXqif" 
guridad jurídica al no perderse el efecto de cosa juzgada que tanto importa al arbitraje.

Respecto del arbitraje ambiental en controversias internacionales contractuales cabe decir que existen importantes esfuerzos para someter tales disputas a tribunales especializados, mediante la creación de reglas y centros entendidos en la materia. Sin embargo, en materia de inversión, donde la jurisdicción deriva de un tratado y no de un contrato, serán los tribunales quienes construyan y determinen a través del case law, la procedencia y forma de aplicación del arbitraje ambiental en el espectro internacional. 